\title{
EKSPLORASI ETNOMATEMATIKA BENTUK ANYAMAN DAUN LONTAR KEBUDAYAAN LAMAHOLOT
}

\author{
Maria Nirmala Hospa Gawen ${ }^{1}$, Gregorius Taga ${ }^{2}$ Konstantinus Denny Pareira Meke ${ }^{3}$ \\ ${ }^{1}$ Program Studi Pendidikan Matematika Universitas Flores, Jalan Sam Ratulangi, Ende-Flores-NTT \\ ${ }^{2}$ Universitas Flores, Jln. Sam Ratulangi, Ende-Flores-NTT \\ ${ }^{3}$ Universitas Flores, Jln. Sam Ratulangi, Ende-Flores-NTT \\ E-mail: marianirmala04@gmail.com
}

\begin{abstract}
Mathematics studied in school is abstract and has no benefit in their life or culture, so mathematics is hard for students to understand. However, students do not realize that mathematical concepts have applied in everyday life. Ethnomathematics is an approach that links mathematics and culture very closely. One of them is a form of woven motifs made of palm leaves that is related to mathematical concepts. This study aims to: 1) Identify the motives found in palm leaf matting in the Lamaholot culture. 2) Knowing the relationship between palm leaf woven motifs in the Lamaholot culture with mathematics learning in schools. The research method used is qualitative with an ethnographic approach. Data collection used observation, interviews and documentation. The data analysis techniques used were observation, interview and documentation. The results showed that the woven motif of palm leaves has a relationship with mathematics. In the woven motif of palm leaves in the form of a flat geometric shape, the dese woven motif has a rhombus plane geometric shape and osan has a parallelogram geometric shape, the sebeng and sodong woven motifs have an isosceles triangle flat geometric shape and the woven klekar motif has a shape hexagon plane geometry. But the people in Atawai Village do not know that the culture they apply and use is related to learning mathematics.
\end{abstract}

Keywords: ethnomathematics; matting; geometry.

\begin{abstract}
Abstrak
Matematika yang dipelajarai di sekolah adalah hal yang abstrak dan tidak mempunyai manfaat dalam kehidupan maupun budaya mereka sehingga matematika sangat sulit dipahami oleh siswa. Namun siswa tidak menyadari bahwa sudah diterapkan konsep matematika dalam kehidupan sehari-hari. Etnomatematika merupakan satu pendekatan yang mengaitkan antara matematika dan budaya yang sangat erat. Salah satunya bentuk motif anyaman yang terbuat dari daun lontar yang memiliki keterkaitanya dengan konsep matematika. Penelitian ini bertujuan untuk: 1) Mengidentifikasi motif-motif yang terdapat pada anyaman daun lontar dalam kebudayaan lamaholot. 2) Mengetahui hubungan motif-motif anyaman daun lontar pada kebudayaan lamaholot dengan pembelajaran matematika di sekolah. Metode penelitian yang digunakan adalah kualitatif dengan pendekatan etnografi. Pengumpulan data yang digunakan observasi, wawancara dan dokumentasi. Teknik analisis data yang digunakan adalah observasi, wawancara dan dokumentasi. Hasil penelitian menunjukan bahwa motif anyaman dari daun lontar memiliki kaitan dengan matematika. Pada motif anyaman dari daun lontar berbentuk bangun geometri bidang datar yaitu motif anyaman dese mempunyai bentuk geometri bidang datar belah ketupat dan osan memunyai bentuk geometri bidang datar jajar genjang, motif anyaman sebeng dan sodong mempunyai bentuk geometri datar segitiga sama kaki dan motif anyaman klekar mempunyai bentuk geometri bidang datar segi enam. Tetapi masyarakat di Desa Atawai yang tidak tahu bahwa kebudayaan yang mereka terapkan dan gunakan mempunyai keterkaitan dengan pembelajaran matematika.
\end{abstract}

Kata kunci: etnomatematika; anyaman; geometri

\section{PENDAHULUAN}

Pendidikan merupakan suatu kebutuhan hidup yang sangat penting bagi manusia, karena itu melalui pendidikan manusia dapat mengembangkan potensi yang ada pada dirinya melalui proses 
Eksplorasi Etnomatematika Bentuk Anyaman Daun Lontar Kebudayaan Lamaholot

Maria Nirmala Hospa Gawen ${ }^{1}$, Gregorius Taga ${ }^{2}$ konstantinus Denny Pareira Meke ${ }^{3}$

Jupika: Jurnal Pendidikan Matematika, Volume 4. Nomor 1. Maret 2021. Hal. 52-61

pembelajaran sehingga mampu memenuhi kebutuhan hidupnya. Menurut Normina (2017:18) mengataka bahwa melalui perwarisan kebudayaan dan internalisasi pada setiap individu, pendidikan hadir dalam bentuk sosialisasi kebudayaan, berinteraksi dengan nilai-nilai masyarakat setempat dan memelihara hubungan timbal balik yang menentukan proses-proses perubahan tatanan sosio-kultur masyarakat dalam rangka mengembangkan kemajuan peradabannya. pendidikan dan kebudayaan merupakan dua unsur yang memiliki hubungan yang sangat erat dimana keduanya memiliki suatu hal yang sama yaitu nilai-nilai. Dalam suatu budaya pendidikan sangat berperan penting dalam pengajaran nilai-nilai budaya.

Pengembangan pengetahuan matematika siswa dapat dilakukan melalui integrasi pendidikan matematika dan budaya yang bermakna untuk menumbuhkan kemampuan siswa, mengembangkan warisan budaya sesuai konteks masa kini menggunakan basis keterampilan berpikir kreatif matematis. Berpikir kreatif yang dikembangkan melalui integrasi matematika dan budaya bercirikan logis, rasional, imajinatif yang disertai dengan rasa estetika (Wulandari \& Kadek, 2016:35-36). Matematika yang ada pada masyarakat berkembang sesuai dengan kebudayaan setempat dan merupakan pusat proses pembelajaran dan metode pembelajaran. Pembelajaran matematika dikatakan sebagai pembelajaran kontekstual sehingga dapat memberikan pengalaman serta wawasan baru bagi siswa. Melalui etnomatematika pembelajaran akan memperkenalkan tradisi maupun budaya lokal yang masih diakui. Menurut Fajriyah (2018:117) Pembelajaran matematika berbasis budaya (etnomatematika) merupakan salah satu cara yang dipersepsikan dapat menjadikan pembelajaran matematika lebih bermakna dan kontekstual yang berkaitan erat dengan komunitas budaya. Renggi (2019:96) mengatakan bahwa etnomatematika merupakan ide-ide matematika, pemikiran dan praktek matematika yang didasarkan oleh budaya suatu kelompok tertentu, dan dianggap sebagai suatu kejadian tentang gagasan matematis. Selain itu, pembelajaran matematika berbasis budaya akan menjadi alternatif pembelajaran yang menarik, menyenangkan, dan inovatif karena memungkinkan terjadinya pemaknaan secara kontekstual berdasarkan pada pengalaman siswa sebagai anggota suatu masyarakat budaya sehingga diharapkan dapat turut serta mendukung gerakan literasi.

Siswa memerlukan perubahaan cara berpikir tentang matematika dimana mereka menganggap matematika yang dipelajarai di sekolah adalah hal yang abstrak dan tidak mempunyai manfaat dalam kehidupan maupun budaya mereka. Matematika merupakan salah satu mata pelajaran yang sangat sulit dan rumit dianggap oleh siswa. Hal ini cukup memperihatinkan mengingat matematika memliliki objek yang bersifat abstrak sehingga pemahaman siswa membutuhkan daya pikir tinggi. Menurut Rahmawati \& Muchlian (2019:125) karakteristik matematika yang abstrak, menyebabkan banyak siswa masih berada dalam keadaan cemas jika mempelajari matematika dan kebudayaan siswa mengalami kesulitan dalam mengaplikasikan matematika ke dalam situasi kehidupan real. Tanpa kita sadari masyarakat telah melakukan berbagai aktivitas dengan menggunakan konsep dasar matematika dan ide-ide matematis. Misalnya, aktivitas jual beli (menghitung uang kembalian, untung, rugi), 
Eksplorasi Etnomatematika Bentuk Anyaman Daun Lontar Kebudayaan Lamaholot

Maria Nirmala Hospa Gawen ${ }^{1}$, Gregorius Taga ${ }^{2}$ konstantinus Denny Pareira Meke ${ }^{3}$

Jupika: Jurnal Pendidikan Matematika, Volume 4. Nomor 1. Maret 2021. Hal. 52-61

aktivitas mengukur (panjang, luas, berat, volume), dan aktivitas berhitung. Kurang kontekstual dan bersifat semu. Pembelajarannya pun kurang bervariasi, bentuk pembelajaran yang terlalu terpaku terhadap buku, kurangnya media pembelajaran berbasis lokal dan kurangnya guru berkreativitas dalam menciptakan pembelajaran atau media pembelajaran dalam konteks kehidupan sehari-hari, kehidupan berbudaya dalam hal ini budaya lamaholot.

Etnomatematika adalah hasil aktivitas suatu suku yang didalamnya terdapat konsep-konsep matematika yang kadang tanpa disadari oleh masyarakat itu sendiri (Zayyadi, 2017: 36-37). Menurut Rahmawati \& Muchlian (2019: 127-128) pada dasarnya perkembangan matematika sampai kapanpun tidak terlepas dari budaya dan nilai yang telah ada pada masyarakat maka penelitian etnomatematika perlu mendapat ruang. Fujiati \& Mastur (2014:179) mengatakan bahwa dalam penerapan pembelajarannya berbasis etnomatematika memungkinkan guru dan siswa beradaptasi aktif berdasarkan budaya yang sudah mereka kenal. Sebagai media pembelajaran, budaya dan beragam perwujudannya dapat menjadi konteks dari contoh tentang konsep atau prinsip dalam suatu mata pelajaran, serta menjadi konteks penerapan prinsip atau dalam suatu mata pelajaran. Pembelajaran berbasis etnomatematika merupakan salah satu bentuk aplikasi yang sangat penting diterapkan dalam dunia pendidikan formal. Hal ini penting karena mendekatkan siswa pada budaya dan dunia nyata yang dekat dengan kehidupannya sehari-hari (Fauzi \& Lu'luilmaknun, 2019: 417-418).

Budaya dan masyarakat adalah dua unsur yang saling melekat, karena terdapat hubungan timbal balik antara kebudayaan dengan masyarakat, sebagaimana ada hubungan antara kebudayaan, peradaban dan sejarah. Masyarakat dapat menghasilkan kebudayaan, sedangkan kebudayaan itu menentukan corak dari masyarakat itu sendiri. Jadi antara manusia dan kebudayaan merupakan suatu kesatuan yang memiliki hubungan yang sangat erat. Pembelajaran berbasis budaya dapat dibedakan menjadi tiga macam, yaitu belajar tentang budaya, belajar dengan budaya, dan belajar melalui budaya. Etnomatematika merupakan sebagai satu pendekatan yang mengaitkan antara matematika dan budaya, pengaitan ini diharapkan mampu meningkatkan kecintaan siswa terhadap budaya sehingga membuat siswa dapat mengetahui manfaat matematika dalam perspektif budaya (Astutiningtyas, ddk, 2017:112).

Menurut D'e Ambrosio (Dominikus, 2018: 8) makna kata etno tidak hanya terkait dengan etnis atau kelompok budaya saja tetapi juga termasuk dalam hal lain budaya seperti jargon, kode, simbol, mitos bahkan cara-cara tertentu dalam masyarakat. Etnomatematika sendiri juga dapat diterapkan dalam pembelajaran disekolah berbasis budaya. Sebelum menerapkan budaya dalam pembelajaran, hal terpenting yang harus dilakukan adalah mengenal, memahami, dan mengeksplorasi budaya itu sendiri. Menurut Hurit (2019:309) Etnomatematika merupakan salah satu pendekatan yang dapat digunakan untuk menjelaskan bahwa budaya masyarakat dan matematika memiliki kaitan yang sangat erat dan merupakan sebuah rumpun ilmu pengetahuan (Wahyuni, 2021). 
Eksplorasi Etnomatematika Bentuk Anyaman Daun Lontar Kebudayaan Lamaholot

Maria Nirmala Hospa Gawen ${ }^{1}$, Gregorius Taga ${ }^{2}$ konstantinus Denny Pareira Meke ${ }^{3}$

Jupika: Jurnal Pendidikan Matematika, Volume 4. Nomor 1. Maret 2021. Hal. 52-61

Kofi dan Nahak (2020:17) dalam hasil penelitiannya menyatakan bahwa penggunaan LKS berbasis etnomatematika yang valid, praktis, dan efektif dapat mengoptimalkan pembelajaran siswa. Hal ini berarti bahwa dalam kegiatan pembelajaran matematika dapat menggunakan LKS yang dirancang menggunakan pendekatan etnomatematika. Kegiatan pembelajaran matematika dengan mengeksplorasi budaya menjadi sangat menyenangkan bagi siswa. Dalam prosesnya ada interaksi antara guru dengan siswa dan siswa dengan siswa yang saling berdiskusi sehingga pembelajaran menjadi lebih hidup (Irawan \& Kencanawaty, 2017: 80) .

Di sekolah yang dominan suku atau etnis tertentu yang seringkali mengajarkan matematika yang tidak bisa mengunakan bahasa Indonesia demikian juga pada beberapa daerah dimana dalam bahasa pengantar juga menggunakan bahasa setempat. Oleh karena itu guru harus mengajarkan matematika dengan menggunakan bahasa pengantar dari bahasa setempat. Bahasa daerah setempat mempunyai istilah sendiri, misalnya: dese (sokal), osan (tikar), sebeng (tempat tembako), sodong (tempat siri, pinang dan kapur), klekar (nyiru). Kata-kata seperti ini mempunyai makna begitu banyak bagian dan guru untuk mengajarkan matematika formal dalam komputasi. Pertimbangan lain bahwa matematika yang diperoleh disekolah tidak cocok dengan cara hidup masyarakat setempat, sehingga matematika sangat sulit dipahami oleh siswa karena ada dua skema yang diperoleh yaitu skema yang diperoleh di lingkungan dan skema yang diperoleh di sekolah.

\section{METODE}

Jenis penelitian yang digunakan dalam penelitian ini adalah penelitian kualitatif dengan pendekatan etnografi. Dalam pendekatan etnografi peneliti berupaya mendeskripsikan serta menggambarkan secara rinci perilaku manusia pada lingkungan budaya. Tempat dilaksanakan penelitian berada pada Desa Atawai Kecamatan Nagawutung Kabupaten Lembata, yang berlangsung pada Juli s.d Agustus. Penelitian melibatkan 4 subjek, yaitu pengrajin anyaman, Tetua adat, Pejabat desa dan guru mata pelajaran matematika.

Teknik pengumpulan data dalam penelitian ini yaitu obsevasi, wawancara dan dokumentasi. Dalam observasi digunakan teknik partisipasi pasif, dimana peneliti datang ke tempat penelitian namun hanya sebagai pengamat tanpa ikut berperan sebagai apapun. wawancara yang digunakan adalah wawancara semi terstruktur, dimana pertanyaan didalam wawancara disusun terlebih dahulu oleh peneliti sebagai pedoman dalam pelaksanaanya. Namun pertanyaan tersebut memiliki kemungkinan untuk berkembang. dokumentasi ini bertujuan untuk mendokumentasikan proses pengumpulan data serta mendokumentasikan bagian motif dari anyaman tersebut. Instrumen yang digunakan dalam penelitian ini adalah pedoman observasi dan pedoman wawancara.

Teknik analisis data yang digunakan pada penelitian yaitu data yang diperoleh melalui observasi, wawancara dan dokumentasi dianalisis dengan menggunakan metode analisis yaitu terdapat empat aktivitas dalam analisis data: (1) pengumpulan data adalah sebuah catatan deskriptif, serta tidak terlepas dari catatan yang peneliti catat berdasarkan pendapat peneliti dari hasil pengamatan terhadap 
objek penelitian; (2) reduksi data adalah mulai memilih dan memilah data, membuat batasan-batasan antara data yang diperoleh yaitu menetapkan data yang relevan dan yang tidak relevan; (3) pemaparan data adalah data dipaparkan dengan tujuan agar mudah dilihat ataupun mudah menentukan pola- pola dan mudah dibanding- bandingkan. Pada pemaparan data ini dipaparkan dengan bahasa yang singkat; (4) penarikan kesimpulan data adalah diberikan kesimpulan-kesimpulan yang sesuai. Sebelum hasil kesimpulan digunakan, maka hasil kesimpulan harus diverifikasi terlebih dahulu kebenarannya.

\section{HASIL DAN PEMBAHASAN}

dalam kehidupan sehari-hari untuk memenuhi berbagai keperluan masyarakat lamaholot khususnya desa Atawai menggunakan berbagai hasil anyaman dari daun lontar. Anyaman merupakan seni yang mempengaruhi kehidupan dan kebudayaan masyarakat lamaholot. Menganyam berarti menyilangkan bahan-bahan dari daun lontar untuk dijadikan satu rumpun yang kuat dan boleh digunakan. Hasil dari anyaman itu diantaranya klekar (nyiru), dese (sokal kecil), osan (tikar), sebeng ( tempat menyimpan siri pinang dan tembakau serta daun lontar yang di potong untuk dijadikan untuk menyimpan roko), sodong (tempat menyimpan siri, pinang dan kapur). Konsep-konsep matematika pada anyaman Lamaholot kebanyakan mengandung unsur geometri. Bentuk dasar membentuk pola geometri dua dimensi berbentuk bangun datar, salah satu contohnya yaitu motif pada masing-masing anyaman. Sedangkan untuk yang tiga dimensi berbentuk bangun ruang, salah satu contohnya yaitu bentuk bakul yang telah digunakan. Hal ini menunjukkan bahwa anyaman bambu dapat digunakan sebagai pembelajaran matematika (Suciati \& Kusuma, 2019: 258) (Wurdani \& Budiarto, 2021).

Tabel 1. Bentuk dan konsep matematika pada motif anyaman

\begin{tabular}{|l|l|}
\hline $\begin{array}{l}\text { Anyaman tikar dibentuk dari beberapa helaian } \\
\text { daun lontar dan menghasilkan anyaman } \\
\text { berbentuk persegi panjang dengan panjangnya } \\
\text { 2 meter dan lebar 1 meter. Dari bentuk lipatan } \\
\text { dau lontar tersebut menghasilkan motif } \\
\text { berbentuk jajar genjang. }\end{array}$ \\
\hline \\
$\begin{array}{l}\text { Motif Dese Baku merupakan suatu anyaman } \\
\text { yang dibentuk dari helaian daun lontar } \\
\text { dimana bagian alas bakul tersebut berbentuk } \\
\text { persegi dan bagian tampang atasnya berbentuk } \\
\text { lingkaran dan berdiameter 45 cm dan tinggi } \\
\text { bakul 30 cm. anyaman bakul ini memiliki motif } \\
\text { yang dibentuk dari lipatan daun lontar } \\
\text { berbentuk belah ketupat. }\end{array}$ \\
$\begin{array}{l}\text { Anyaman sebeng dan sodong merupakan } \\
\text { anyaman yang dibentuk dari lipatan daun } \\
\text { lontar, dimana sebeng berbentuk balok, } \\
\text { dengan tingginya 20 cm, panjangnya 15 dan } \\
\text { lebar 10 cm sedangkan sodong pada bagian } \\
\text { alasnya berbentuk persegi dan bagian tampang } \\
\text { atasnya berbentuk lingkaran berdiamater 20 } \\
\text { cm dan tingginya 25 cm. Kedua anyaman ini } \\
\text { juga mempunyai motif yang sama berbentuk }\end{array}$ \\
\hline
\end{tabular}




\begin{tabular}{|l|l|}
\hline & Segitiga. \\
\hline & $\begin{array}{l}\text { Klekar merupakan sebuah anyaman yang } \\
\text { terbuat dari helaian daun lontar yang dilipat } \\
\text { dan membentuk sebuah tabung dimana } \\
\text { diameternya } 60 \mathrm{~cm} \text { dan tingginya } 5 \mathrm{~cm} . \text { Klekar } \\
\text { juga mempunyai kekhasan tersendri yaitu } \\
\text { motifnya berbentuk segi enam beraturan } \\
\text { dimana segi enam itu terbentuk dari gabungan } \\
\text { tiga bangun datar jajar genjang. }\end{array}$ \\
\hline
\end{tabular}

Dalam proses membuat anyaman ada beberapa tahap yang harus diperhatikan dalam pembuatan, sebelumnya kita harus menyediakan bahan dan alat yang dibutuhan, paling penting yang di butuhkan dalam pembuatan anyaman daun lontar, lontar yang baik yang digunakan untuk membuat anyaman yaitu lontar yang berumur 30-40 tahun atau bisa di bilang semakin tinggi pohonnya daun yang dihasilkan lebih baik, tinggi pohon tersebut mencapai 15-30 meter bahkan bisa melebihi itu, daun lontar yang digunakan adalah bagian pucuk daun lontar karna memiliki tekstur yang lunak dan mudah untuk dibentuk (Fajar, Sunardi \& Yudianto, 2018). Daun lontar yang sudah di ambil dijemur paling lama satu hari guna menghilangkan kadar air hingga nol, daun lontar pun dipisahkan dari tulang daunnya (tikar), setelah di pisahkan dari tulang daunnya daun lontar pun di suwir (lelir) ada beberapa jenis suwiran. Ada yang di suwur (lelir) selebar satu sentimeter, ada yang dua tergantung keinginan dan kebutuhan.Ukuran yang di gunakan dalam membuat ukuran suwiran daun lontar biasa disebut belelir (tulang daun lontar yang dilipat menjadi dua bagian dan sudah di tentukan ukuran yang diinginkan), belelir ini dibantu oleh pisau yang digunakan untuk menuwir daun lontar dan siap untuk dianyam. Dari hasil anyaman itu dibuat bentuk motif yang diinginkan dan disesuaikan untuk membentuk motifnya, adapun motif itu diberi warna biar kelihatan menarik itu semua tergantung pengrajin inginkan.

Hasil anyaman tersebut mempunyai ukuran dan bentuk yang berbeda-beda. Bakul memiliki bentuk yang sangat berbeda dimana bagian alas nya berbentuk persegi dan bagian tamangnya berbentuk lingkaran berdiameter $45 \mathrm{~cm}$ dan tinggi $30 \mathrm{~cm}$ dengan motifnya berbentuk belah ketupat. Anyaman tikar memiliki bentuk persegi panjang dengan panjangnya $2 \mathrm{~m}$ dan lebarnya $1 \mathrm{~m}$ dari hasil anyaman membentuk motif berupa bangun datar jajar genjang. Sebeng dan sodong merupakan kedua anyaman mempunyai bentuk yang berbeda dimana sebeng merupakan anyaman berbentuk balok dengan tingginya $20 \mathrm{~cm}$ panjangnya $15 \mathrm{~cm}$ kebarnya $10 \mathrm{~cm}$ dan sodong merupakan anyaman dimana bagian alasnya berbentuk persegi dan tampang atasnya berbentuk lingkaran dengan diameternya 25 $\mathrm{cm}$ dan tingginya $20 \mathrm{~cm}$ kedua anyaman ini memliliki motif yang sama yaitu segitiga . sedangkan anyaman nyiru merupakan sebuah anyaman berbentuk tabung dimana diameternya $60 \mathrm{~cm}$ dan tingginya $5 \mathrm{~cm}$ dan memliki motif berbentuk segi enam dimana gabungan dari tiga bangun datar jajar genjang. 
Eksplorasi Etnomatematika Bentuk Anyaman Daun Lontar Kebudayaan Lamaholot

Maria Nirmala Hospa Gawen ${ }^{1}$, Gregorius Taga ${ }^{2}$ konstantinus Denny Pareira Meke ${ }^{3}$

Jupika: Jurnal Pendidikan Matematika, Volume 4. Nomor 1. Maret 2021. Hal. 52-61

Kegunaan setiap anyaman untuk kehidupan sehari-hari maupun dalam pelaksanaan upacara adat bakul yang dibuat ini merupakan salah satu barang yang terbuat dari daun lontar. Besar kecilnya bakul tergantung jenis lontar (panjang dan pendeknya daun lontar) dan ukuran yang suwir (lelir). Kegunaan dari bakul ini digunakan untuk menyimpan hasil kebun (padi, jagung, dll), kapas dan benang untuk memenun, sarung, dll. Tikar merupakan suatu alat yang paling dibutuhkan dalam kehidupan seharihari, dalam keseharian tikar digunakan untuk tidur, tikar (osan) ini juga digunakan untuk mengalas hasil panen untuk dijemur dan membersihkan padi (memilahkan bernas padi dari tangkainya). Klekar dengan nama lainya nyiru yang digunakan untuk membersihkan beras dan jagung dari kotoran, klekar juga biasa digunakan sebagai wadah meletakan barang adat (gelang gading dan sarung adat ) saat melakukan transaksi belis (poe bala). Sebeng dan sodong merupakan dua benda yang memiliki fungsi yang sama yaitu menyimpan barang, namun barang yang di simpan adalah berbeda. Sebeng ini digunakan untuk menyimpan barang milik pria yaitu tembakau (tbako) dan daun lontar yang sudah dikikis dan di potong sepanjang jari tengah, sedangkan sodong digunakan dalam menyimpan siri, pinang dan kapur. Sebeng ini dimiliki oleh bapak-bapak dan sodong digunakan oleh mamamama.Dalam upacara adat setiap orang sudah tau posisi merka masing masing, biasanya mama-mama dan bapak-bapak yang lebih tua dalam suku tugasnya adalah untuk fajak. Fajak adalah bapak yang bertugas memberi tembakau dan daun lontar tersebut kepada tamu yang datang untuk membuat rokok (tebakor), sedangkan ibu-ibu memberi siri pinang dan kapurnya kepada tamu yang datang untuk makan (sin). Menurut aparat desa mengatakan bahwa generasi sekarang dan yang akan datang dituntut untuk bisa menganyam dan selalu menggunakan perlengkapan anyaman karna itu semua merupakan warisan nenek moyang.

Melalui kajian produk budaya yang berkaitan dengan konsep matematika dalam anyaman budaya lamaholot, menunjukkan kemampuan yang tinggi dari masyarakat tersebut dalam berpikir kreatif (Isnaini, 2019: 31) (Laurens, Kempa \& Serpara, 2020:79). Hal ini berarti bahwa etnomatematika pada kerajinan anyaman rakyat Lamaholot dapat dimanfaatkan sebagai sumber belajar dalam pembelajaran matematika, memberikan pengetahuan dan menambah wawasan siswa tentang matematika pada unsur budaya yang dekat dengan kehidupan siswa sehari-hari (Abi, 2016:5). Pembeljaaran etnomatematika membuat siswa mampu dan lebih mudah menjebatani dan membuat siswa memahami konsep matematika dan meningkatkan motivasi mereka serta memfasilitasi siswa dalam mengaitkan konsep-konsep yang dipelajari dengan situasi dunia nyata (Puspadewi \& Putra, 2014:88)(Prabawati, 2016:30)(Resfaty, Muzdalipah \& Hidayat, 2019).

Tikar (osan) pada anyaman memiliki motif yang sama berupa bentuk bangun datar jajargenjang. Motif ini merupakan susunan daun lontar yang dapat membedakan bentuknya.motif tergantung helaian daun yang disuwir (lelir). Anyaman dese memiliki motif tersendiri yaitu berbentuk belah ketupat. Kegunaan dari bakul ini digunakan untuk menyimpan hasil kebun (padi, jagung, dll), kapas dan benang untuk memenun, sarung, dll. Pada anyaman lamaholot lainnya, terdapat begitu banyak motif 
Eksplorasi Etnomatematika Bentuk Anyaman Daun Lontar Kebudayaan Lamaholot

Maria Nirmala Hospa Gawen ${ }^{1}$, Gregorius Taga ${ }^{2}$ konstantinus Denny Pareira Meke ${ }^{3}$

Jupika: Jurnal Pendidikan Matematika, Volume 4. Nomor 1. Maret 2021. Hal. 52-61

segitiga yang mengelilingi sodong dan sebeng. Pada motif klekar tidak memiliki makna tersendiri, hanya mengandung nilai seni dan itu sudah menjadi kebiasaan untuk bentuk anyaman nyiru. Unsur matematika yang terkandung di dalam anyaman tradisional ini berupa konsep geometri bidang (Fauzi \& Lu'luilmaknun, 2019) yang terdapat pada anyaman yang digunakan oleh para penganyam, konsep kesebangunan dan kekongruenan. Selain itu, Etnomatematika yang ada pada kerajinan anyaman Lamaholot adalah adanya penggunaan prinsip teselasi/pengubinan pada pola anyaman. Pola anyaman yang ada pada klekar (nyiru), dese (sokal kecil), osan (tikar), sebeng, sodong (tempat menyimpan siri, pinang dan kapur). menggunakan prinsip teselasi. Teselasi tersebut menggunakan bangun geometri yaitu persegi panjang dan segitiga (Puspadewi \& Putra, 2014:88) (Ubayanti, Lumbantobing \& Manurung, 2016: 20-21). Hasil dari penelitian ini sebagai rujukan untuk penelitian berikutnya dan dapat diterapkan dalam pembelajaran matematika di kelas. Lebih lanjut, pengetahuan masyarakat lokal perlu dikaji lebih lanjut untuk menemukan berbagai pengetahuan yang dapat dijadikan kearifan lokal untuk pengembangan karakter siswa dan mata pelajaran sekolah.

\section{KESIMPULAN}

Berdasarkan hasil analisis data dan pembahasan, dapat disimpulkan bahwa hasil eksplorasi etnomatika pada budaya lamaholot ditemukan beberapa benda yang berasal dari anyaman daun lontar. Benda-benda tersebut memiliki bermacam-macam motif, dan motif-motif itu relevan dengan bentukbentuk bangun geometri yang diajarkan di sekolah. Benda-benda tersebut adalah Osan, Dese, Sebeng dan Sodong, klekar. Pada anyaman osan motifnya berbentuk jajar genjang, dalam pembelajaran matematika di sekolah guru menjelaskan konsep jajar genjang sebagai bangun datar yang memiliki dua sisi berhadapan sama panjang dan sejajar serta diagonalnya membagi dua sama. Anyaman dese motifnya berbentuk belah ketupat, dalam pembelajaran matematika di sekolah guru menjelaskan konsep belah ketupat yang keempat sisinya sama panjang dan sudut-sudutnya membagai dua sama besar oleh diagonal-diagonalnya. Anyaman sebeng dan sodong motifnya berbentuk segitiga dalam pembelajaran matematika di sekolah guru menjelaskan konsep segitiga sebagai bangun datar yang memiliki tiga sisi saling bertumpu. Anyaman klekar motifnya berbentuk segi enam beraturan, dalam pembelajaran matematika di sekolah guru menjelaskan konsep segi enam beraturan sebagai bangun datar yang memiliki 6 sisi sama panjang dan 6 sudut yang sama besar. Bagi peneliti selanjutnya disarankan untuk melakukan penelitian tentang etnomatematika pada permainan tradisional lainnya. Tidak hanya permainan, namun bisa menggunakan unsur-unsur budaya lain untuk dijadikan sebagai media pembelajaran matematika.

\section{DAFTAR PUSTAKA}

Abi, A. M. (2016). Integrasi Etnomatematika Dalam Kurikulum Matematika Sekolah. Jurnal Pendidikan Matematika Indonesia. 1(1), 1-6 
Eksplorasi Etnomatematika Bentuk Anyaman Daun Lontar Kebudayaan Lamaholot Maria Nirmala Hospa Gawen ${ }^{1}$, Gregorius Taga ${ }^{2}$ konstantinus Denny Pareira Meke ${ }^{3}$ Jupika: Jurnal Pendidikan Matematika, Volume 4. Nomor 1. Maret 2021. Hal. 52-61

Astuningtyas, E. L., Wulandari, A. A., \& Farahsanti, I. (2017). Etnomatematika Dan Pemecahan Masalah Kombinatorik. Jurnal Math Educator Nusantara: Wahana Publikasi Karya Tulis Ilmiah Di Bidang Pendidikan Matematika,3(2), 111-118. https://doi.org/10.29407/jmen.v3i2.907

Dominikus, W.S. (2018). Etnomatematika Adonara. Malang: Media Nusa creative

Fajar, F. A., Sunardi, S. \& Yudianto, S. (2018). Etnomatematika Pembuatan Kerajinan Tangan Anyaman Bambu Masyarakat Osing di Desa Gintangan Banyuwangi Sebagai Bahan Ajar Geometri Kadikma. 9(3), 97-108.

Fajriyah, E. (2018). Peran Etno terkait konsep matematika dalam mendukung literari. Prisma: Posiding seminar Nasional matematika. 1(2018), 114-119

Fauzi, A. \& Lu'luilmaknun, U. (2019). Etnomatematika pada permainan dengklaq sebagai media pembelajaran matematika. Aksioma: Jurnal Program Studi Pendidikan Matematika. 8(3), 408419. doi: https://doi.org/10.24127/ajpm.v8i3.2303

Fujiati, I. \& Mastur Z. (2014). keefektifan model POGIL berbantuan alat peraga berbasis Etnomatematika terhadap kemampuan komunikasi matematis. Unnes Journal of Mathematics Education. 3(3), 174-180

Hurit, R. U. dan Suarsono, St. (2019). Kajian Etnomatematika Rumah Adat Koko Bala Dan Pakaian Tradisional Di Lewotala Kabupaten Flores Timur (NTT). Proseding Sendika. 5(1). 308-316

Isnaini, L. (2019). Kerajinan Tenunan Anyaman Bali Terdapat Unsur Etnomatematika. Jurnal MathEducation Nusantara. 2 (1), , 28-34

Irawan, A. Kencanawaty, G. (2017). Implementasi Pembelajaran Matematika Realistik Berbasis Etnomatematika. Journal of Medives: Journal of Mathematics Education IKIP Veteran Semarang. 1(2), 74-81

Kofi1, M. D. \& Nahak. S. (2020). Mengoptimalkan Skemata Siswa Menggunakan Lembar Kerja Siswa Berbasis Etnomatematika: Anyaman Dan Tenunan Masyarakat TTU. Range: Jurnal Pendidikan Matematika. 2(1), 8 - 17

Laurens, T., Kempa, R., \& Serpara, H. (2020). The Ethnomathematics of Tutuwaru Community in The Crafts of Koli Leaf Weaving. Jurnal Pendidikan Matematika (Jupitek), 3(2), 71-80. https://doi.org/10.30598/jupitekvol3iss2pp71-80

Normina (2017). Pendidikan Dalam Kebudayaan. Ittihad: Jurnal Kopertais Wilayah XI. 15(28) 17-28

Prabawati, M. N. (2016). Etnomatematika Masyarakat Pengrajin Anyaman Rajapolah Kabupaten Tasikmalaya. Infinity Journal. 5(1), 25-31

Puspadewi, K. R. \& Putra, I. G. N. N. (2014). Etnomatematika di Balik Kerajinan Anyaman Bali. Jurnal Matematika. 4(2), 80-89. https://doi.org/10.24843/JMAT.2014.v04.i02.p47.

Rahmawati. Z. Y. \& Muchlian, M (2019). Eksplorasi Etnomatematika Rumah gadang Minangkabau Sumatra Barat. Jurnal Analisa 5(2), 124-129

Renggi A. S. J. (2019). "Etnomatematika Dalam Kerajinan Tangan Anyaman Masyarakat Desa Watukamba Kecamatan Maurole Kabupaten Ende. Prosiding Sendika. 5(1), 94-102 
Resfaty, A. G., Muzdalipah, I. \& Hidayat, E. (2019). Studi Etnomatematika: Mengungkap Gagasan dan Pola Geometris Pada Kerajinan Anyaman Mendong di Manonjaya Kabupaten Tasikmalaya. Journal of Authentic Research on Mathematics Education (JARME) Vol. 1, No. 1, Januari 2019, pp. 19-26

Suciati, R. \& Kusuma, A. B. (2019). Eksplorasi Etnomatematika Pada Anyaman Bambu. Prosiding Sendika. 5(1), 252-259

Ubayanti, C. S., Lumbantobing, H. \& Manurung, M. M. H. (2016). Eksplorasi Etnomatematika pada Sero (Set Net) Budaya Masyarakat Kokas Fakfak Papua Barat. Jurnal Ilmiah Matematika dan Pembelajarannya. 1(1), 12-21

Wahyuni, N. S. (2021). Analisis Etnomatematika Pada Kerajinan Anyaman Bambu Terhadap Pemebelajaran Matematika di Kabupaten Sukabumi. Jurnal PEKA (Pendidikan Matematika) $4(2), 35-40$

Wulandari, I G. A. Pt. A. \& Kadek, R.P. (2016). Budaya dan Implikasinya terhadap pembelajaran matematika yang kreatif. Jurnal Santiaji pendidikan. 6(1), 31-37

Wurdani, W. P. A. K. \& Budiarto, M. T. (2021). Etnomatematika Usaha Kerajinan Anyaman Rotan Masyarakat Gresik dalam Perspektif Literasi Matematis. Jurnal Pendidikan Matematika 12(1), 94-105. doi: http://dx.doi.org/10.36709/jpm.v12i1.15255

Zayyadi, Moh. (2017) "Eksplorasi Etnomatematika pada batik madura". Zigma: Jurnal Pendidikan, $2(2), 35-40$. 